\title{
Mediaciones filosóficas en la teología de la revelación de K. Barth y W. Pannenberg
}

\author{
Serafín BéJAR \\ Facultad de Teología de Granada (España) \\ serabejar@gmail.com \\ (1) https://orcid.org/0000-0002-3170-5367
}

Resumen: La revelación en Barth y Pannenberg es una cuestión abundantemente estudiada. Sin embargo, no siempre aparece suficientemente explicitada la temática de las mediaciones filosóficas que dichos teólogos utilizan para hablar de la revelación. Esta cuestión es crucial porque nos permite ubicar la pregunta por la revelación en el campo específico de la credibilidad. Por este motivo, el objetivo de este trabajo consiste en evidenciar el principio formal-fundamental que estos dos teólogos han encontrado para dotar a sus respectivas teologías de un carácter único. En el caso de Barth, la diferencia dialéctica se constituye en el principio formal de su pensamiento, y en el caso de Pannenberg la estructura anticipatoria de la razón histórica es la óptica formal-fundamental de su propuesta.

Palabras claves: Barth, Pannenberg, teología dialéctica, Schleiermacher, Dilthey.

Abstract: Revelation in Barth and Pannenberg is an abundantly studied question. However, the topic of the philosophical mediations that these theologians use to talk about Revelation does not always appear sufficiently explicit. This question is crucial because it allows us to place the question of Revelation in the specific field of credibility. For this reason, this paper aims at highlighting the formal-fundamental principle that these two theologians have found to endow their respective theologies with a unique character. In the case of Barth, the dialectical difference is constituted in the formal principle of his thought, and in the case of Pannenberg the anticipatory structure of historical reason is the formal-fundamental perspective of his proposal.

Keywords: Barth, Pannenberg, dialectical theology, Schleiermacher, Dilthey. 


\section{INTRODUCCIÓN}

El punto de partida en común de las teologías de Karl Barth y Wolfhart Pannenberg es la recuperación de la escatología dentro del ámbito propiamente cristiano. De ahí el protagonismo de la revelación en ambas propuestas, ya que esta recuperación escatológica es la condición que posibilita que la voz de Dios pueda escucharse en el escenario de la historia. Ahora bien, surge la cuestión de si esta voz divina necesita unas determinadas modulaciones de razón que permitan su mediación en un momento histórico concreto ${ }^{1}$. La pregunta podría formularse de la siguiente manera: ¿cómo se relacionan eternidad y tiempo? ¿cómo conciliar la revelación y la historia? ${ }^{2}$.

Con esta pregunta tocamos el corazón mismo de la labor teológica. En concreto, nuestra convicción consiste en que el teólogo cumple con su misión cuando es capaz de aportar un principio, de naturaleza formal-fundamental, que realiza esta específica labor de mediación (intellectus fidei). Dicho principio, brotando de la escucha de la fe del proprium cristiano (auditus fidei), atiende a las declinaciones de razón que son propias de un determinado tiempo histórico (auditus temporis) ${ }^{3}$.

El objetivo del presente artículo consiste en individuar el principio formal-fundamental que encontramos en la teología de la revelación de dos de los autores protestantes más significativos del siglo xx: Barth y Pannenberg. Nos parece que este ejercicio es tremendamente pertinente para mostrar el genio teológico de cada uno de estos pensadores. En efecto, en dicho principio reconoceremos la comprensión que ambos tienen de la entraña misma del cristianismo, al tiempo que seremos capaces de examinar la asimilación que ellos han realizado de la aventura de emancipación moderna. Este principio es denominado "formal" porque establece la manera en la que han de entenderse todos y cada uno de los contenidos definitorios del cristianismo. Y se adjetiva como "fun-

1 Cf. G. Ruggieri, "Cristianesimo. Una denominazione modulata dalla sua storia", Cristianesimo nella storia 23 (2002) 1-52 y B. ForTe, Sui sentieri dell'Uno (Morcelliana, Brescia 2002) 233-236.

2 Cf. H. Fries, "La revelación”, en J. Feiner y M. Löhrer (dirs.), Misterium Salutis, I, (Cristiandad, Madrid 1969) 209.

3 Cf. S. BÉJAR, Donde hombre y Dios se encuentran. La esencia del cristianismo en $B$. Forte y O. González de Cardedal (Edicep, Valencia 2004) 311-326. 
damental" porque atiende a la específica dimensión de credibilidad que ha de tener como objetivo irrenunciable cualquier esfuerzo teológico ${ }^{4}$.

En definitiva, queremos poner de manifiesto que la teología es siempre un esfuerzo históricamente condicionado, ya que la eternidad no es aprehensible sino a la manera humana en la que se da a nosotros. Incluso en el caso de Barth, que en su primera etapa muestra displicencia a cualquier forma de mediación, podemos sentir la necesaria apelación a determinadas modulaciones de razón.

\section{KARL BARTH: LA REVELACIÓN DESDE LA MEDIACIÓN DE LA DIFERENCIA DIA- LÉCTICA ENTRE TIEMPO Y ETERNIDAD}

Algunos autores, con cierto tono irónico, afirman que Barth ${ }^{5}$ recibió una formación muy poco barthiana ${ }^{6}$. En efecto, en los años de su juventud adoptó las influencias de la teología de su tiempo, de corte netamente liberal. Sin embargo, los dolorosos acontecimientos vitales, a los que se tiene que enfrentar, provocarán en el propio Barth la fuerza necesaria para contener las influencias recibidas y revertirlas de una manera profundamente contracultural. Tenemos aquí no solo el paso de la "teología liberal" a la "teología dialéctica", sino la explicitación de la búsqueda de

4 Cf. S. BÉJAR, "Método teológico y credibilidad del cristianismo", Theologica Xaveriana 64 (2014) 25-58.

5 Nuestro acceso al pensamiento del teólogo calvinista debe mucho al trabajo de B. Forte, especialmente a su obra teológica Simbolica ecclesiale. Para todo lo que viene a continuación, ver La parola della fede. Introduzione alla Simbolica ecclesiale (San Paolo, Milano, 1996) 33-37; La teología come compagnia, memoria e profezia. Introduzione al senso e al método della teologia come storia (San Paolo, Milán ${ }^{2} 1996$ ) 124; Trinità come storia. Saggio sul Dio cristiano (San Paolo, Milán ${ }^{5} 1993$ ) 79s.; Teologia della storia. Saggio sulla rivelazione, l'inizio e il compimiento (San Paolo, Milán $\left.{ }^{2} 1991\right)$ 49-54. 297ss. Fuera de la Simbolica es importante, ante todo, la obra Cristologie del Novecento (Queriniana, Brescia, ${ }^{3} 1995$ ) donde, en la primera parte, "La storia nelle cristologie del Novecento", se habla de Barth en las p. 13-20 y, especialmente, en la segunda parte del mismo libro, "Cristologia e Politica", dedicado íntegramente a la figura de Barth, 63-104.

6 Cf. K. BARTH, Introduzione alla teologia evangelica (Edizione Paoline Milano, 1990) 240-265. Las páginas indicadas son un apéndice de esta obra con la autobiografía de Barth en relación a Schleiermacher. Por tanto, todo lo referente a sus acontecimientos vitales, así como a sus influencias intelectuales, son tomadas de relato que realiza el propio teólogo calvinista. 
una mediación válida entre un tiempo concreto y la propia fe cristiana, como la tarea propia del teólogo.

El resquebrajamiento de la teología que Barth había recibido tiene que ver con un episodio icónico de la historia de Europa, y también de su propia existencia. En los albores del estallido de la primera contienda bélica mundial, con motivo de la política de guerra del káiser Guillermo II, los grandes teólogos liberales de aquel tiempo firman un manifiesto de apoyo a su propuesta. Esto supone para el joven Barth una cierta conmoción: que la teología de ese momento se muestre tan complaciente en apoyar el statu quo, sin ninguna relevancia critica, sin reclamo alguno de ulterioridad, como si se pudiera confundir el Reino de Dios con un determinado orden político o social, es lo que va a terminar rompiendo por dentro a este creyente. La firma en dicho manifiesto de sus maestros de antaño, incluyendo a A. von Harnack, genera en él un proceso de conversión que lo lleva más allá de las formas propias de la teología liberal, en la cual había sido educado ${ }^{7}$.

A partir de este momento, Barth quiere mostrar que la teología debe ser vigilante, para que el Reino de Dios nunca se confunda con el mundo, puesto que el Reino de Dios es una instancia escatológica. Ésta es una dimensión que va a estar muy presente en su teología: la dimensión escatológica de su pensamiento, que en él se convierte en un "no" a toda realidad terrena que reivindique para sí cualquier forma de definitividad. A su juicio, "absolutamente nada tiene que ver con Cristo un cris-

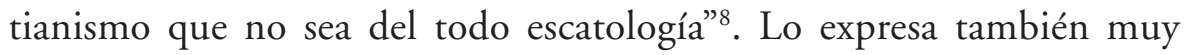
bien J. Moltmann:

Después de la primera guerra mundial los fundadores de la "teología dialéctica" situaron en el centro de su labor no solo exegética, sino también dogmática, a la escatología, que había quedado reprimida idealísticamente del modo antes dicho y condenada a la ineficacia. Programáticamente lo expresa Karl Barth en la segunda edición de su obra La carta a los Romanos?.

Así es, no hay institución, ni sistema, ni forma de pensamiento que, bajo el sol de este mundo, pueda reclamar unas cuotas de cumplimiento, plenitud o reconciliación, que solo pueden ser atribuidas a Dios. $\mathrm{Cu}$ -

7 Cf. K. BARTH, Introduzione, 243.

8 K. BARTh, Carta a los romanos (BAC, Madrid 1998) 381.

9 J. Moltmann, Teología de la esperanza (Sígueme, Salamanca 1969) 48. 
riosamente, este ingreso de la escatología en el pensamiento teológico tendrá, en el teólogo calvinista, unas implicaciones políticas nada desdeñables, especialmente visibles en su decidido posicionamiento en contra de la divinización del Führer, en la Alemania de los años treinta.

Con esto que decimos, podemos caer en la cuenta de que Barth es testigo privilegiado de un cambio de época, caracterizada por el paso de un tiempo reconciliado a otro tiempo violento y en crisis. El teólogo protestante analizará, por tanto, los testimonios más preclaros de esta aparente reconciliación, siendo muy crítico con ellos. En concreto son tres: la reconciliación en el concepto de la filosofía y teología hegeliana, la reconciliación en el sentimiento de la obra de F. Scheleiermacher y la reconciliación de la teología liberal que se entiende a sí misma como ciencia. Vayamos por partes.

Barth realiza un reproche de calado a la asunción que el hegelianismo hace del cristianismo: la identificación del espíritu absoluto con Dios. Esta identificación construye una imagen de Dios que es esclavo de sí mismo, ya que, para Hegel, el espíritu, por necesidad, tiene que manifestarse, de tal forma que la revelación es una consecuencia necesaria de la esencia misma de dicho espíritu. Sin embargo, Barth quiere reivindicar la absoluta soberanía de Dios, su libertad plena, que hace de Dios, no un esclavo de sí mismo, sino decididamente libre ${ }^{10}$. En esta asimilación entre espíritu absoluto y Dios, el teólogo calvinista visibiliza la rendición de la teología de su tiempo al buen juicio imperante, de modo que se produce una domesticación del fenómeno cristiano por parte de la modernidad. En efecto, la libertad queda reducida a necesidad que se determina a sí misma, el tiempo es la propia eternidad en su movimiento de despliegue, el ser humano es el espíritu que se hace consciente de sí mismo y el drama de lo negativo queda como momento necesario que conduce a la reconciliación. He aquí la confusión de toda una época.

10 Cf. K. BARTh, Die protestantische Theologie im 19. Jahrhundert (Evangelische Verlagsanstalt, Berlin 1961) 343-378. En una conferencia, tenida en 1949, con el título de La actualidad del mensaje cristiano, podemos leer: "La decisión de Dios de manifestarse como Dios del hombre, dando en Jesucristo el propio reconocimiento, no tiene nada que ver con la naturaleza de Dios, no depende de hecho de una necesidad pre-establecida, sino que es su soberana, creadora, misericordiosa decisión y acción”, en K. BARTH, L'umanità di Dio. L'attualità del messaggio cristiano (Claudiana, Torino 2010) 10. 
En palabras del propio Hegel, hablando del cristianismo como religión absoluta:

La religión absoluta es el saber de que Dios es la profundidad del Espíritu cierto de sí mismo, con lo que es el sí mismo de todos. Éste es la esencia, el puro pensamiento; pero, despojado de esta abstracción, Dios es el sí mismo real, es un hombre, con una existencia espacial y temporal corriente; $y$ todos los singulares son este singular, la naturaleza divina no es distinta de la humana [...] La religión absoluta, en cambio, es la emergencia a la luz de lo profundo, profundidad que es el yo, que es el concepto, el puro poder absoluto ${ }^{11}$.

Del mismo modo, las críticas de Barth al pensamiento hegemónico de su tiempo tienen que ver con ciertas confusiones que, el teólogo calvinista, ve ya presentes en F. Schleiermacher, a quién considera el padre de los teólogos liberales. En su obra Sobre la religión. Discursos a sus menospreciadores cultivados de 1799, Schleiermacher manifiesta su convicción de que la religión no se funda ni en la metafísica, ni en la moral, sino que tiene una región antropológica propia, al lado del conocimiento y de la praxis: "Que la religión surja de por sí del interior de cada alma mejor, que a ella le pertenezca una provincia propia en el ánimo, en la que impera de un modo ilimitado"12. También aquí encontramos el reflejo del pensamiento de una época, concretamente de un romanticismo idealista, donde la religión queda reducida a un sentimiento de dependencia infinita: "Porque no se tenía religión; porque el sentimiento de lo infinito no lo animaba; porque el anhelo de este infinito y la veneración del mismo no constreñían sus finos pensamientos etéreos a asumir una consistencia más firme"13. De hecho, para Schleiermacher el objeto de la religión no es primariamente un Dios transcendente, sino el universo, donde lo infinito hace su aparición en lo finito. Este panlogismo, con una clara conexión con Spinoza, le resulta a Barth inaceptable, porque lleva al ser humano a una cima de identificación tal con el absoluto, que se hacen evidentes los peligros de un proceso tal de auto-exaltación. Así, será significativa la contradictoria influencia de este autor, durante la etapa dialéctica a la que nos estamos refiriendo, aun cuando años más tarde el propio Barth lo califique de "padre de la Iglesia del siglo XIX y XX"14. Hablando de la

\footnotetext{
11 G.W.F. Hegel, Filosofía real (FCE, México 1984) 41.

12 F. Schleiermacher, Sobre la religión (Tecnos, Madrid 1990) 25.

13 F. Schleiermacher, Sobre la religión, 37.

14 K. BARTH, Introduzione, 239.
} 
teología de Bultmann, refiere Barth las influencias de Schleiermacher en el teólogo existencial, de una manera muy viva:

¡Una vez más el mensaje cristiano anunciado a la escucha de la pretensión decisiva de la sociedad y del mundo contemporáneo! ¡Una vez más la simbiosis típica de Schleiermacher entre teología y filosofía! ¡Una vez más una antropologización de la teología tan obvia como aquella con la cual Schleiermacher, en su época, llevó a cumplimiento la doctrina sobre Dios del siglo XVIII y, al mismo tiempo, fundó la del siglo XIX! ¡Una vez más la unidad en tensión de objeto y sujeto, magistralmente descrita en el segundo de sus Discursos! ¡Y una vez más la originaria y final unidad de ambas, triunfalmente proclamada: la gloriosa eliminación del esquema sujeto-objeto! ${ }^{15}$

Avanzando en nuestra argumentación, podemos afirmar que la última de las confusiones de su tiempo hace referencia a la teología liberal y su pretensión de cientificidad. Barth nos dice que toda ciencia tiene que adaptar su método al objeto específico de su estudio, y aquí el objeto de la teología es la atención a la voz pura de Dios que ha resonado en su Palabra. Por ello, esto tiene que hacer saltar toda pretensión de cientificidad que sea una forma de castrar, domesticar y reducir, a los límites estrechos de nuestro mundo, aquello que Dios ha dicho de sí mismo.

En este sentido, la teología liberal, con su cercanía a la metodología histórica y crítica, especialmente en el tratamiento de los textos, va a ser criticada por Barth, enemigo tenaz de esta forma de proceder. Hay ciertos elementos de nuestro autor que son muy sugerentes, como reacción indomesticada a un tiempo que cree tener un poder omnímodo. En efecto, la modernidad ha ido ganando vastos espacios al pensamiento y finalmente, abraza de un modo tan fuerte, que produce la asfixia de ciertos ámbitos del saber. $\mathrm{Al}$ asumir los presupuestos de la ciencia contemporánea, la teología acaba enmudecida. O de otro modo, lo que piensa Barth de la teología liberal es que, so capa de cientificidad, acaba privilegiando el método por encima del objeto puro de la fe. En cambio, a juicio del teólogo calvinista, la cientificidad de la teología debería estar en otro sitio: "la teología científica es arrepentimiento, cambio de manera de pensar, 'pensamiento renovado"'16.

15 K. BARTH, Introduzione, 251.

16 K. BARTh, Carta, 605. 
Esta controversia entre teología y ciencia alcanza una cifra densa en referencia a la obra de A. von Harnack, con el conocido texto de $\mathrm{La}$ esencia del cristianismo. En esta propuesta, publicada en el año 1901, encontramos un cristianismo sin cristología, donde el Evangelio se cifra en el Padre, con la consiguiente exclusión del Hijo ${ }^{17}$. Lo verdaderamente interesante de estas afirmaciones es que el propio Harnack otorga a su obra el marchamo de científica, ya que se basa en una metodología rigurosamente histórica. No en vano, en un número de la revista propia de la teología liberal, Christliche Welt, concretamente en el año 1923, Harnack escribe Quince preguntas a los teólogos que desprecian la teología cientifica; artículo que va a ser respondido por el joven Barth con Quince respuestas al profesor von Harnack ${ }^{18}$. Aparece aquí, por tanto, los datos básicos de una más de las grandes controversias que, el primer Barth, acaudilló en su tiempo.

Así pues, y a juicio de nuestro teólogo, esta pretensión de reconciliación del conjunto de lo real (Hegel, Schleiermacher y Harnack) era uniformidad, apariencia, hybris humana que quería acortar las distancias y, por ello, provocó el auto-engrandecimiento prometeico que lleva finalmente a la violencia. Barth propone como antídoto, a este titánico esfuerzo, la obediencia a la revelación. De este modo, la crisis por la que pasa Barth va a dar inicio a una nueva corriente teológica que tendrá por nombre, como hemos apuntado, "teología dialéctica". El punto de partida es la asunción de la Palabra de Dios, como algo ya dado, más allá de cualquier forma de sabiduría humana y, más aún, de toda pretensión de crear sistemas cerrados o totales.

Es así como nos encontramos con un positivismo de la revelación, donde ésta queda identificada con la Palabra misma de Dios, cuya aparición acontece en la objetivación de las Sagradas Escrituras. No obstante, esto no significa que Barth caiga en un literalismo bíblico, ya que él mismo reivindica la necesidad de escuchar la Palabra en un desbordamiento de las palabras, yendo más allá de la mera atención a la letra. De hecho, y en contraste con ciertas posturas conservadoras dentro del protestantismo de su tiempo, realizó una comprensión de la inspiración de las Escrituras que reivindicaba el espíritu, mucho más que el apego

17 Cf. A. von Harnack, La esencia del cristianismo (Henrich y Cía, Barcelona 1904) 67. 18 Para atender a esta confrontación, cf. J. Moltmann (ed.), Le origini della teologia dialettica (Queriniana, Brescia 1976) 375-402. 
a la mera letra. De este modo, Barth reclama cómo el significado de las Escrituras requiere de una atención a un contenido que, en gran medida, está aún por descubrirse. Surge así la demanda, por parte del teólogo, de una decidida apelación a la intuición: "Y he ahí que el Antiguo y el Nuevo Testamento comenzaron a hablarme"19.

Todo esto que decimos se ve de manera representativa en una obra que va a tener una gran repercusión en su tiempo: su comentario a la carta a los Romanos de 1919. Es interesante hacer notar cómo todo autor protestante que se precie, más tarde o más temprano, tiene que acometer la labor de confrontarse con la teología paulina contenida en esta carta. No en vano, nuestro teólogo fue un gran conocedor de los orígenes de la reforma y de las figuras de Lutero y Calvino, principalmente. La acogida de esta obra de Barth, no exenta de polémica, va a provocar la necesidad de una segunda edición renovada, en un periodo de tiempo relativamente corto, concretamente en 1922. Con este motivo, escribe un nuevo prólogo, donde aprovecha para contestar a los ataques que había recibido por la primera edición de la misma. En el prólogo a la segunda edición, a este comentario a la epístola a los romanos, se hace una pregunta determinante: ¿de qué es de lo que se habla ahí? ¿cuál es el tema de la Palabra de Dios? Y, con una fuerza inspiradora, que toma de S. Kierkegaard, nos dice que ahí, en eso dado, que es la Palabra de Dios, se habla de la diferencia infinita e irreductible entre el tiempo y la eternidad ${ }^{20}$. Las propias palabras del filósofo danés afirman que "toda la confusión de los tiempos modernos [...] consiste en haber abolido el abismo inmenso de la diferencia cualitativa entre Dios y el hombre"21. Esto podría traducirse de una manera muy plástica: Dios está en el cielo, mientras que el ser humano está en la tierra. Por lo tanto, la Palabra de Dios, como irrupción de lo eterno en el tiempo, es juicio para este mundo. De esta necesidad de mantener la separación entre trascendencia e inmanencia, reivindicando su innegable distancia, viene la adjetivación con la que va a ser bautizada su propuesta: "dialéctica". Podemos atender a la fuerza de sus propias palabras:

19 K. Barth, Carta, 244. Cf. también prólogo a la segunda edición, en Carta, 56s., donde distingue entre el Evangelio real, al que dedica sus desvelos, del Evangelio entero.

20 Para clarificar la influencia de Kierkegaard en Barth, cf. B. FORTE, Fare teologia dopo Kierkegaard (Morcelliana, Brescia 1997) 9-21.

21 C. Fabro (ed.), Diario. Soren Kierkegaard, I, (Morcelliana, Brescia 1948) 381. 
¿Qué quiero dar a entender cuando digo que la dialéctica interna del asunto y su conocimiento en la letra del texto son el factor decisivo de la comprensión y de la explicación? Se me dice [...] que con ello se quiere indicar solo mi "sistema" [...] A eso debo señalar lo siguiente: si tengo un sistema, éste consiste en no perder de vista la significación negativa y positiva de lo que Kierkegaard llamó la "infinita diferencia cualitativa" que existe entre tiempo y eternidad. "Dios está en el cielo y tú en la tierra". La relación de este Dios con este hombre, la relación de este hombre con este Dios es para mí el tema de la Biblia y el compendio de la filosofía ${ }^{22}$.

No hay elemento de homogeneidad entre el tiempo y la eternidad, no hay elemento de uniformidad entre Dios y el hombre, entre Iglesia y mundo: eso es dialéctica. Por lo tanto, toda pretensión de reducir esta novedad indeducible de la Palabra de Dios a los presupuestos que brotan de nuestra propia subjetividad es idolatría. El ser humano, ante esta Palabra de Dios que le viene dada, tiene que experimentarla como juicio a su propia vida:

Si Dios se revela al hombre, a este hombre en este mundo, tiene que contraponerse a él como el que se enoja con él, como el que manifiesta de modo irresistible su poder en él, es decir, le demuestra de modo inevitable e inexorable que él no se identifica con ninguno de los dioses a los que el hombre adora, ni siquiera con el dios supremo ${ }^{23}$.

Aquí encontramos un evidente contraste con la teología de su tiempo. La crítica fundamental a la teología liberal hegemónica, realizada por el propio Barth, es haber anulado la epifanía de Dios para reducirla a presupuestos meramente humanos, provocando una fraudulenta reconciliación entre lo divino y lo humano: "hablar de Dios (para la teología liberal) significaba hablar, con un tono más elevado, del hombre" ${ }^{24}$. En el citado prólogo a la segunda edición, Barth hace alusión a las críticas de su coetáneo Paul Wernle, reconocido especialista de la escuela de la historia de las religiones, que lo acusa de una doctrina complicada, falta

\footnotetext{
K. BARTh, Prólogo a la segunda edición, en Carta, 54.

K. Barth, Carta, 428.

24 K. BARTH, L'umanità, 18. Esta obra, ya citada anteriormente, está editada por Sergio Rostagno, y recoge algunas conferencias del propio Barth, así como algunos estudios sobre su trabajo teológico. En concreto, acabamos de citar su conferencia "La humanidad de Dios", tenida en 1956, donde el teólogo realiza ya una revisión crítica de su propio itinerario, ponderando aquello que aún resulta válido de la teología dialéctica, y aquello que ha de ser matizado.
} 
de llanura y sencillez para el cristiano medio. La respuesta a estas apreciaciones muestra la imagen que tiene Barth de la teología de su época, así como una resuelta fuerza de confrontación con sus propios colegas de antaño:

¿Qué debo responderle? ¿No es obvio que yo solo podría dejarle contento si me decidiera a abandonar la quebrada línea de la fe y decir aquello bien conocido, manejable, directo, no paradójico, que en el reino de la verdad, en el reino de lo totalmente infantil y de lo totalmente no infantil es lo tercero, lo excluido? Sin duda, bien que me gustaría poder hablar sencillamente de aquello de lo que se trata en la Carta a los romanos [...] Pero hasta ahora, entre los que hablan "sencillamente" solo he encontrado a aquellos que, sencillamente, hablan de otra cosa distinta y que, por consiguiente, no pueden convertirme a su sencillez ${ }^{25}$.

Ante este proceso de indiferenciación, propio de un siglo burgués que hacía crisis, podemos entender la fuerza del programa dialéctico, en sentido barthiano, como la diferencia insuprimible entre Dios y el ser humano. Barth dirá que la Palabra de Dios ha de cuestionar todas nuestras ideas humanas. Lo único que le cabe al hombre, delante de este Dios vivo, es una rendición obediente. No en vano, en la Biblia no encontramos una teología humana sobre Dios, sino más bien una antropología divina sobre el hombre: "No podremos esconder que el mensaje cristiano no trata ni del humanismo clásico, ni de aquel que hoy se quiere descubrir, sino del humanismo de Dios" ${ }^{26}$. El contraste, por tanto, entre Hegel o Schleiermacher y Kierkegaard es patente, y de nuevo podemos constatar la influencia del filósofo danés en la articulación teológica que Barth otorga a su pensamiento. De hecho, estas palabras del filósofo danés, poniendo distancia entre Dios y su creación, corroboran nuestras afirmaciones:

La naturaleza, la totalidad de la creación, son la obra de Dios, y sin embargo, Dios no está ahí, pero en el interior del hombre individual existe una posibilidad de despertar en la interioridad a la relación con Dios y es así como es posible ver a Dios en todas partes ${ }^{27}$.

25 K. Barth, Prólogo, 50.

26 K. BARTH, L'attualità, 8.

27 S. KierKegaArD, El concepto de angustia (Guadarrama, Madrid 1965) 244. 
Podemos notar cómo Barth es un crítico de la línea hegemónica de la modernidad, ya que no acepta sus presupuestos. Hay que abandonar todos los conceptos humanamente creados para recibir en fe aquello que Dios piensa sobre el mundo, aquello que Dios piensa sobre el hombre y aquello que Dios piensa y dice de sí mismo. Así es, la aparición del Dios vivo supone "la crisis de todas las fuerzas, lo totalmente distinto" 28.

Esto que venimos diciendo aparece también en otra forma de dialéctica que está en el corazón del pensamiento barthiano: la fuerte tensión entre religión y fe. La religión es la pretensión humana de hablar sobre Dios. Por eso, la religión es siempre un intento idólatra y, así mismo, fallido: "La realidad de la religión es lucha y escándalo, pecado y muerte, demonio e infierno" ${ }^{29}$. Es necesario abandonar el ámbito de lo religioso para insertarnos en otra atmósfera, que es la de la $\mathrm{fe}^{30}$. Todo lo que el hombre diga sobre Dios está radicalmente corrompido, distorsionado. No podemos perder de vista que la antropología protestante, en este caso calvinista, es una antropología con un marcado tono negativo. Así, el hombre únicamente tiene que acoger en la fe, aquello que Dios muestra de su misterio. Como se podrá notar, la teología que encontramos en la Carta a los Romanos no se debe entender como oferta positiva de contenidos concretos, a propósito del cristianismo, sino de una manera puramente negativa, que se traduce en un mero desmentido de todos nuestros puntos de vista. De hecho, la cristología que se nos propone, en el comentario a esta epístola, no atiende a los misterios de la vida de Cristo, ya que todo se resume en hacer de la encarnación refutación del mundo y de lo humano.

Continuando en esta senda, encontramos otro elemento dialéctico en nuestro autor: la controversia entre la analogia entis y la analogia fidei. Esta cuestión va a conocer una evolución desde posturas más radicales, en la primera etapa de germinación de su pensamiento, hasta un momento posterior donde, en diálogo con la teología católica, y especialmente con la obra del jesuita E. Przywara, Analogia Entis, se irán

\footnotetext{
K. BARTh, Carta, 84.

K. BARTh, Carta, 322.

30 Afirma Kierkegaard: "la verdadera religiosidad es oculta interioridad", en Postscriptum no cientifico y definitivo a "Migajas filosóficas" (Sígueme, Salamanca 2010) 495.
} 
matizando sus afirmaciones ${ }^{31}$. La analogia entis, dice Barth, es un invento del demonio, y desde ahí critica fuertemente al catolicismo. Hay que abandonar toda pretensión de alcanzar a Dios por medio de la creación, para ubicarnos en otro suelo: nunca es posible alcanzar a Dios, y hay que abrirse a la sorpresa de que Dios sí ha alcanzado nuestro mundo gracias a su revelación. Éste sería un dato definitorio del cristianismo, en contraste con los diversos universos religiosos, ante los que Barth se muestra tremendamente escéptico. Son conocidas las palabras, en las que afirma: "considero que la analogia entis es la invención del Anticristo y pienso que, debido a ello, yo no puedo hacerme católico"32. De nuevo, podemos encontrar aquí influencias de la lectura de Kierkegaard:

Entre Dios y el ser humano [...] hay una diferencia absoluta; por tanto, la relación absoluta de una persona con Dios debe expresar específicamente la diferencia absoluta, y la semejanza directa se vuelve insolencia, vanidosa pretensión, presunción, y demás ${ }^{33}$.

En este primer Barth, el de la teología dialéctica, percibimos una desconfianza radical en la realidad creatural, porque para la tradición protestante, la creación está absolutamente corrompida por el pecado, a la manera de un espejo roto que no puede reflejar correctamente nada de Dios. A este respecto, son clarificadoras las palabras que H. Fries refiere, hablando de Barth: "Dios está escondido, el hombre está ciego"34. En efecto, los entes, si estuvieran en el ámbito de la gracia, podrían transparentar a Dios, pero al estar en el ámbito del pecado, toda pretensión de alcanzar el cielo desde el ser humano, que es criatura, o a través de las cosas creadas, provoca irremediablemente una distorsión de Dios mismo: "El Reino de Dios es el Reino de Dios. No podemos pensar de manera suficientemente radical el paso de las analogías divinas a la realidad humana" ${ }^{35}$. En el fondo, lo que aquí encontramos es una puesta en crisis de toda forma de mediación. La analogía solo es pensable en el

31 Cf. O. González de Cardedal, El quehacer de la teología (Sígueme, Salamanca 2008) 430-433.

32 K. Barth, K., Die Kirchliche Dogmatik, I/1 (Evangelischer Verlag, Zürich 1955) VII. Sus palabras son: "Ich halte die analogia entis für die Erfindung des Antichrist und denke, dass man ihretwegen nicht katholisch werden kann".

33 S. Kierkegaard, Post-scriptum definitivo, 403.

34 Cf. H. Fries, "La revelación", 219.

35 E. Busch, Karl Barth. Biografia (Queriniana, Brescia 1977) 99. Son palabras tomadas de una conferencia en Arburgo en 1919. 
ámbito de la gracia y de la fe. De ahí que, basándose en el texto de Rm 12,6 , considere el ejercicio de la analogía como aquella correlación que se establece en la interpretación de unos textos bíblicos a la luz de otros. Por tanto, tenemos una dialéctica más, aquella de se da entre la analogia entis, propia de la religión, y la analogia fidei, forma peculiar de la fe.

A pesar de todo lo dicho, es interesante anotar que el mismo teólogo hará una revisión de esta primera etapa de su vida, dando lugar a un nuevo barthismo, perceptible especialmente en la Dogmática eclesial, donde la "dialéctica" se suaviza como "dialógica". En esta nueva etapa reconoce que ha hablado de Dios de una manera muy poco humana, ya que, pretendiendo salvaguardar la absoluta indeducibilidad de Dios y su carácter inmanipulable, ha convertido el Evangelio, no en buena noticia, sino en juicio ${ }^{36}$. El Barth dialéctico nos dirá que la resurrección del Hijo de Dios toca a nuestro mundo como "la tangente a un círculo" ${ }^{37}$; es decir, en un punto, y es en dicho punto donde su manifestación se convierte en juicio: desmentido de todas las formas de pensar, juicio de todos los pecados y de toda forma de existencia religiosa. Sin embargo, el propio Barth va a reconocer, en un momento posterior de su vida, la necesidad de pasar del Dios "contra" el hombre a un Dios "para" el hombre, moderando así sus propias afirmaciones. En efecto, pretendiendo salvaguardar la pureza del objeto de la teología, que es la Palabra de Dios, se había corrido el riesgo de acabar corrompiendo al otro polo del quehacer teológico: el ser humano en su dignidad. No en vano, en su Introducción a la teología evangélica, fruto de unas lecciones dictadas durante el curso 1961-1962, podemos leer unas afirmaciones que no dejan de ser sorprendentes, habida cuenta de todo lo dicho hasta el momento:

Con su trabajo, la teología evangélica responde a aquel sí de gracia de parte de Dios, al auto-anunciarse de Dios en su benignidad para el hombre. Ésta tiene que ver con Dios en cuanto Dios del hombre, al tiempo que con el hombre como hombre de Dios [...] Entonces el término teología, estrictamente hablando, es insuficiente para expresar el significado de la teología evangélica, porque no pone en evidencia esta dimensión decisiva de su objeto, es decir, el libre amor de Dios que suscita el libre amor del hombre, su gracia que llama a

36 Para este proceso de replanteamiento de sus presupuestos teológicos, Cf. K. BARTH, L'umanità, 17-23. Se trata de una conferencia tenida en Aarau en 1956.

37 K. BARTh, Carta, 78. 
la gratitud. El término "teo-antropología" podría indicar mejor de quién y de qué cosa se trata en la teología evangélica ${ }^{38}$.

La teología dialéctica jugó un papel profético en un enclave histórico muy doloroso y ofreció un giro novedoso a la teología, que quedó profundamente grabado en la conciencia de su tiempo. El quehacer teológico comienza a realizarse atendiendo a un extra nos, a una medida que no ha sido establecida por el propio hombre. Barth se atrevió a reivindicar la revelación de Dios, que ha hablado por medio de su Palabra, como el único criterio de verdad que puede otorgar salvación a nuestro mundo.

\section{Wolfhart Pannenberg: La revelación desde la mediación de la eS- TRUCTURA ANTICIPATORIA DE LA RAZÓN HISTÓRICA}

Es común en el protestantismo entender la revelación como autorevelación; es decir, como la identidad entre Dios mismo y su manifestación. De hecho, aquí podemos cifrar una de las aportaciones más importantes de Hegel al cristianismo: revelación significa que Dios se da a sí mismo. En palabras del propio Pannenberg:

La teología cristiana tiene, pues, una gran deuda con Hegel: la idea de Dios como infinito verdadero, la renovación, a ella vinculada, de la doctrina trinitaria y del dogma de la encarnación, la comprensión de la revelación como auto-revelación de Dios y, por último, la relación de la revelación con la Trinidad ${ }^{39}$.

Ahora bien, aparece, dentro de la unanimidad de esta cuestión en la Reforma protestante, un elemento de diferenciación: la auto-revelación de Dios, ¿se realiza de un modo directo o indirecto ${ }^{40}$ La postura de Pannenberg, que dará lugar a un manifiesto de jóvenes teólogos en el año 1961, conocidos como el círculo de Heidelberg, es clara: la revelación de Dios se efectúa a través de la mediación de las acciones divinas obradas en el escenario de la historia ${ }^{41}$. Lo expresa en forma de tesis:

38 K. BARTH, Introduzione, 62.

39 W. Pannenberg, Una historia de la filosofía desde la idea de Dios (Sígueme, Salamanca 2002) 329.

40 Cf., para esta cuestión, la importante obra de W. PANNENBERG y otros, La revelación como historia (Sígueme, Salamanca, 1977) 11-27. Estas páginas corresponden a la Introducción, escrita por el propio Pannenberg.

41 Para una panorámica global del pensamiento y la obra de este autor, Cf. J.A. MARTínez Camino, "Introducción”, en W. PannenberG, Teología sistemática, I (Universidad Pontificia Comillas, Madrid 1992) IX-XXIX. 
"Según los testimonios bíblicos, la auto-revelación de Dios no se ha realizado de una forma directa, algo así como en la forma de una teofanía, sino indirectamente, a través de las obras de Dios en la historia" ${ }^{42}$. Estas gestas son suficientes por sí mismas, aunque no son "hechos brutos", ya que se insertan en una comunidad de tradición, dentro de la cual se decodifica el significado de estas gestas históricas con las que Dios se manifiesta en la historia. De esta manera, Pannenberg quiere alejar el concepto de revelación de toda significación arcana, destinada a una minoría selecta, o incluso de cualquier determinación gnóstica, a la manera de un conocimiento elevado. Afirma nuestro teólogo:

En este lenguaje de los hechos ha revelado Dios su divinidad. Para percibir esto no se necesita añadir nada en absoluto a los hechos revelatorios -los cuales, naturalmente, no tienen que verse como bruta facta sino en su propio contexto en la historia de la tradición-, al menos, nada que nos permitiera ver en los sucesos algo distinto de lo que puede conocerse a partir de ellos mismos ${ }^{43}$.

Con lo expuesto hasta ahora, podemos establecer algunos contrastes, dignos de mención, con respecto a otros autores protestantes. En primer lugar, con Hegel: mientras que Pannenberg entiende la revelación como historia, el filósofo alemán entiende la historia como revelación. En efecto, es importante hacer notar que no es la historia la que revela a Dios, sino que son los actos de dicho Dios, obrados en la historia, los que revelan su rostro. Y no es esto lo que afirma Hegel. Para él, la historia es revelación, ya que el "calvario" de objetivación del espíritu absoluto, en su proceso de reapropiación y reconciliación, no es otro que el proceso histórico.

En segundo lugar, el contraste con Barth: si para el teólogo calvinista la revelación se realiza de modo directo en su Palabra, para el teólogo protestante la revelación acontece de modo indirecto por medio de acciones históricas ${ }^{44}$. Además, para Pannenberg las palabras están siempre subordinadas a los acontecimientos históricos en los que Dios se manifiesta: "El kerygma se ha de comprender exclusivamente a partir

42 W. PAnnenberg, "Tesis dogmáticas sobre la doctrina de la revelación”, en PANNENBERG y otros, La revelación, 117.

43 W. Pannenberg, "Tesis”, 129. Para esta misma idea, a propósito de las apariciones del Resucitado, Cf. W. Pannenberg, Fundamentos de cristología (Sígueme, Salamanca 1973) 91.

44 Para estudiar esta cuestión en profundidad, Cf. W. PAnnenberg, Teología, 249-279. 
de su contenido, del acontecimiento que relata y explicita. El kerygma no añade algo nuevo al acontecimiento" ${ }^{45}$. Esta subordinación de las palabras a los hechos históricos es uno de los elementos más criticados de la propuesta de Pannenberg; especialmente la postura que afirma que los hechos se interpretan por sí mismos, sin necesidad de una palabra interpretadora que acontezca desde fuera de los mismos. Esta cierta dicotomía entre hechos y palabras, como si mediara entre ellos una relación meramente extrínseca, es incluso muy discutible desde un punto de vista filosófico ${ }^{46}$. Lo que sí parece claro es que Pannenberg, con respecto a Barth, opera el paso desde una teología de la revelación claramente autoritativa, y de un cierto carácter anti-moderno, a una teología de la revelación más declarativa y expositiva, abierta a dialogar con la modernidad.

Y, en tercer lugar, tenemos las diferencias con R. Bultmann. El punto de contraste con este autor radica en su comprensión de la revelación como ligada a la historia personal del sujeto, donde lo principal reside en que el kerigma impacte en la propia existencia particular. Esta centralidad del elemento existencial adolece, para Pannenberg, de un cierto aislamiento con un todo más amplio de sentido: la historia universal. Así, la revelación entendida de una manera excesivamente biográfica, contrasta con una esencial apelación a la historia, percibida desde su alcance universal y no meramente individual ${ }^{47}$.

Para seguir avanzando en la exposición, es importante aclarar por qué el hecho de que Pannenberg entienda la revelación como historia lo pone en comunicación y en diálogo con la modernidad. En efecto, nuestro teólogo realiza una suerte de discernimiento de las distintas racionalidades y nos dice que las mismas son epocales. No hay una razón que sea absolutamente inmóvil o eterna, sino que el ejercicio del acto de razón debe entenderse como determinado por el sucederse del tiempo y

45 W. Pannenberg, “Tesis”, 145.

46 Para todas estas cuestiones, Cf. A. Dulles, Models of Revelation (Doubleday and Company, New York 1983) 62-67.

47 Cf. W. PAnnenberg, "Acontecer salvífico e historia", en Cuestiones fundamentales de Teología sistemática (Sígueme, Salamanca 1976) 228-232. Puesto que esta obra recoge una colección de artículos del propio Pannenberg, publicados en diversas revistas y volúmenes de colaboración, nos parece apropiado citar el artículo en cuestión al que hacemos referencia. 
los paradigmas de sentido vigentes en un determinado momento y lugar. $\mathrm{O}$ de un modo más categórico aún: no existe la razón tout court ${ }^{48}$.

Así pues, la característica principal de la ejercitación de la razón moderna, según este autor, es su esencial modulación por la historia:

Una razón histórica no es de ninguna manera un mero postulado teológico, sino que el descubrimiento de la historicidad de la razón señala la dirección principal en la que, la comprensión de la razón, ha sido profundizada desde $\mathrm{Kant}^{49}$.

Si esto es así, el problema fundamental de la racionalidad moderna es su dialogo con el futuro. Es aquí donde Pannenberg encuentra un punto de conexión con la fe, ya que la misma también tiene como elemento determinante de su auto-comprensión el componente escatológico; o de otro modo, la fe, por su dimensión escatológica, está constitutivamente abierta al futuro. El punto de unión para dialogar con la racionalidad moderna, compartiendo el mismo foco de interés, será el significado y el sentido de la historia. Afirma nuestro autor:

Y si es solo por respecto al conjunto de la realidad como cabe hablar con sentido acerca de una revelación de Dios en cuanto creador y señor suyo, y, por otra parte, la realidad históricamente entendida se constituye como conjunto de una historia coherente tan solo en razón de un final de todos los acontecimientos, entonces la escatología adquiere un significado constitutivo $[\ldots]^{50}$.

En esta cuestión, que suscitó muchas críticas a los planteamientos de Pannenberg, el teólogo encuentra connivencias muy significativas en el mundo de la filosofía. De hecho, el asunto de la historia tiene que ver, de modo inevitable, con la postulación de una significación de alcance

48 "La teología se enfrenta a esta cuestión (se refiere a la cuestión de la verdad, concomitante con aquella de la razón) dentro de un contexto previamente dado, si bien no aceptable sin reparos de tipo alguno; es el contexto de comprensión occidental de la verdad”, en W. PAnnenberG, “¿Qué es la verdad?”, en Cuestiones, 54.

49 W. Pannenberg, "Glaube und Vernunft", en Grundfragen systematischer Theologie. Gesammelte Aufsätze (Vandenhoeck \& Ruprecht, Göttingen 1967) 247. Es interesante anotar que esta obra se encuentra traducida al español, como ya hemos citado anteriormente, con el título Cuestiones fundamentales de teología sistemáti$c a$. Sin embargo, el trabajo al que hacemos alusión en esta nota, Fe y razón, por motivos que desconocemos, y que no se indican en dicha edición española, no aparece traducido.

50 Cf. W. Pannenberg, "Prólogo", en Cuestiones, 9. 
universal. Además de la influencia, como veremos a continuación, de la filosofía de Dilthey, nuestro autor encuentra confirmación en los planteamientos de J. Habermas:

[...] "implícitamente" todo historiador procede anticipando, desde criterios de la praxis, unos "estados finales desde los cuales la multiplicidad de los acontecimientos se estructura connaturalmente en historias orientadas hacia la acción". Las expectativas del historiador "completan en forma de hipótesis los fragmentos de la tradición pasada, ubicándolos en la totalidad de una historia universal comprendida en anticipación, a cuya luz cada acontecimiento relevante puede en principio quedar descrito tan perfectamente como le resulta posible a la autocomprensión prácticamente operante de una agrupación humana social" ${ }^{\prime \prime}$.

Pannenberg se muestra coincidente con aquella línea de pensamiento, podríamos hablar de K. Löwith, que pone de manifiesto cómo la conciencia histórica de la modernidad es una secularización de la historia tal y como la entiende el judeo-cristianismo ${ }^{52}$. La modernidad, sobre esta base judeo-cristiana, entiende la historia como un continuo abierto al futuro. Y desde esta determinación bíblica, incluye la cuestión helénica de la verdad que, más allá de toda consideración esencialista, comienza a entenderse como realidad en movimiento; incluso, la verdad será concebida como un ir haciéndose. Esto cristaliza de un modo muy significativo en la conciencia moderna, donde el propio Hegel nos invita a pensar la verdad no como substancia inmutable, sino como espíritu en

51 W. PannenberG, "Prólogo", 11. Los entrecomillados son del propio autor, haciendo referencia a J. Habermas, "Zur Logik der Sozialwissenschaften”, PhR Bh 5 (1967) 166.

52 Cf. K. Löwith, El sentido de la historia. Implicaciones teológicas de la filosofía de la historia (Aguilar, Madrid 1956) 35. En la página 282, podemos leer: "Desde que nos preocupa la Historia y el historicismo, estamos inclinados a creer que la moderna conciencia histórica se origina con el pensamiento hebreo y cristiano, esto es, con la consideración escatológica hacia una consumación futura". Para profundizar en estas ideas, también Cf. P. Cerezo Galán, "La secularización. Una cuestión disputada", Anales de la Real Academia de Ciencias Morales y Políticas No 87 (2010) 363-397. 
movimiento ${ }^{53}$. La razón moderna, de este modo, se convierte en razón histórica abierta al futuro ${ }^{54}$.

Es aquí donde juegan un papel importante los ulteriores desarrollos del idealismo alemán, que encontramos de modo muy significado en Dilthey. Para este filósofo, la aparición de la conciencia histórica supone el final decisivo de la visión metafísica de la realidad, que a su juicio había llegado a su máxima expresión en el sistema hegeliano. La separación con respecto a Hegel le lleva a afirmar que todo acontecimiento histórico es finito y relativo: así, toda religión o todo sistema de pensamiento carecen de un valor absoluto.

Pannenberg pone de manifiesto dos aspectos relevantes que contradistinguen a la propuesta de Dilthey de aquella de Hegel: en primer lugar, no hay absoluto que se pueda mediar en la historia; y, en segundo lugar, la anulación de la primacía del concepto, como todo reconciliado, deja espacio a una constitutiva apertura del continuum del tiempo. Estos dos elementos marcan el paso de la "historia", entendida desde una determinación metafísica, al "historicismo", con la pretensión de abandonar toda significación definitiva. Otra cosa muy distinta será si finalmente Dilthey consigue abandonar la denostada metafísica o permanece atrapado en ella.

Es interesante anotar la importancia que tiene la categoría de "vivencia" 55 , tomada de la psicología descriptiva, en la filosofía de Dilthey. Dichas vivencias no tienen un carácter meramente interiorista, porque éstas siempre se expresan objetivamente. Así, todo es una manifestación objetiva de las huellas que nuestras vivencias han dejado en la historia (unos restos arqueológicos, por poner un ejemplo). El en-

53 "Según mi modo de ver, que deberá justificarse solamente mediante la exposición del sistema mismo, todo depende de que lo verdadero no se aprehenda y se exprese como substancia, sino también y en la misma medida como sujeto", en F.W.G. Hegel, Fenomenología del Espiritu (FCE, Madrid 2000) 15.

54 Cf. para esta reflexión, W. PANnEnBerG, “¿Qué es la verdad?”, 53-76.

55 Afirma Heidegger, hablando de Dilthey: "Todo está centrado en la 'psicología', la cual debe comprender la 'vida' en sus conexiones históricas evolutivas y de interacción con el mundo como la manera de ser del hombre, como posible objeto de las ciencias del espíritu y -a la vez- como raíz de estas mismas ciencias. La hermenéutica es el auto-esclarecimiento de este comprender y solo en forma derivada, una metodología de la ciencia histórica”, en M. Heidegger, Ser y tiempo (Trotta, Madrid 2003) $\$ 77$. 
cadenamiento de hechos históricos testimonia las huellas de nuestras vivencias, a la manera de un monumento del espíritu humano, aunque la interpretación de dichas huellas sea siempre relativa ${ }^{56}$.

No obstante, el propio Dilthey es consciente del peligro, subyacente a su postura, de un marcado relativismo y cree encontrar una salida al mismo poniendo en correlación nuestras vivencias con un todo más amplio: la vida. En efecto, nuestras vivencias solo alcanzan consistencia desde una relación de las mismas con la vida entendida como totalidad. Para Dilthey, dotar de un significado a una vivencia particular supone ponerla en correlación con la vida en su conjunto, ya que dicha integridad de vida puede ser experimentada en la parcialidad de las propias vivencias.

Sin embargo, el propio filósofo es consciente de los problemas que genera esta postura. En efecto, si la realidad es un "dable" que se va haciendo en un movimiento progresivo hacia el mañana, nos dirá Dilthey, únicamente visibilizándolas desde el final de la historia podremos saber con claridad el significado de las vivencias. O de otro modo, si asumimos esta racionalidad histórica, en la que vemos la realidad en clave de desarrollo, movimiento o dinamismo, justamente podré establecer el alcance de una determinada vivencia, tanto en el plano personal como en el colectivo, si la contemplo desde su final cumplido. Se trata del paso de una metafísica esencialista a una asunción histórica del ser, donde ya no se trata de conocer la naturaleza de las cosas, sino más bien su historia. Pannenberg hace referencia, en varias ocasiones, a un texto clarificador de Dilthey, que reza como sigue:

Uno tendría que esperar a que la vida llegase a su fin para poder abrazar con la vista, y esto solo en ese instante final, esa totalidad que permite saber cuál es la relación existente entre sus partes. Uno tendría que esperar a que la historia terminase para tener en sus manos todo el material necesario para saber por fin cuál es su significado ${ }^{57}$.

Podemos poner un ejemplo para entender esto. La respuesta a la pregunta por la propia identidad, “¿quién soy yo?”, solo es accesible desde el momento de la muerte. Desde el final de una vida, se tiene un relato completo de toda la historia biográfica y se hace posible responder a esta

56 Cf. M. Garrido, "Historicismo y filosofía de la vida", en M. Garrido y otros (coords.), El legado filosófico y científico del siglo XX (Cátedra, Madrid 2005) 90-94.

57 W. Pannenberg, Una historia, 350. Para dicho texto, Cf. W. Dilthey, Gesammelte Schriften, VII, tomado de la edición de B. Groethuysen de 1926, p. 233. 
pregunta. Todas las respuestas que se den ahora sobre la propia identidad, serán respuestas relativas al fin definitivo, ya que solo desde el término del propio desarrollo biográfico se es capaz de responder de una forma ajustada a la pregunta por la identidad.

Así pues, la solución ofrecida para sortear dicho relativismo, poniendo las vivencias en relación con la vida en su conjunto, no acaba de ser satisfactoria. De hecho, como no poseemos ese todo de la vida de manera definitiva en ningún momento, los significados de los que dotamos a nuestras vivencias se están recolocando a lo largo de nuestra existencia, en un proceso inacabado de reinterpretación. De ahí que la propuesta historicista de Dilthey tenga, a su vez, un marcado tono hermenéutico: "La categoría de significado de Dilthey tomó el lugar de la hegeliana del concepto" 58 .

Es interesante hacer notar cómo, desde estos presupuestos, se podría argumentar que el hecho de responder a la pregunta por el ser de una determinada cosa, se hace bajo el supuesto de un anticipo de un futuro concluido o cumplido, aunque sea de modo atemático e inconsciente. En efecto, Pannenberg opina que solo sobre la base de un adelanto al presente de ese futuro, es decir, sobre la base de una cierta recreación fundada en la fantasía, puedo conocer la realidad o nombrar las esencias. De ahí que el teólogo evangélico dé la vuelta al argumentario de Dilthey; lo cual tendrá, como veremos más adelante, una importancia decisiva a la hora de esclarecer las relaciones entre la razón y la fe:

Dilthey ha sacado a partir de esta visión -que nadie está al final de la historia- la consecuencia resignada de la relatividad de todos los significados que se han defendido. Sin embargo, se debe extraer la consecuencia contraria: cada significado expresado se refiere a un concepto previo, a una anticipación de aquel futuro último, en cuya luz el verdadero significado de cada acontecimiento sería comprendido en principio y definitivamente ${ }^{59}$.

Estas consideraciones alcanzan una nueva articulación en la filosofía de Heidegger que, según reconoce el propio pensador alemán, en relación al Dasein, debe mucho al historicismo de Dilthey. De hecho, consciente del relativismo no resuelto de la propuesta de este último, intenta

58 W. Pannenberg, Una historia, 350.

59 W. Pannenberg, "Glaube", 249. 
ofrecer una solución al mismo con la categoría de "anticipación" ${ }^{0}$. Solo podemos dotar de una significación a nuestras vivencias particulares haciendo un esfuerzo por adelantar el todo de la vida desde la propia muerte, aunque solo sea en potencia. Ahora, aunque estemos sujetos a ulteriores modificaciones del significado de nuestras vivencias, podemos escapar del relativismo, especialmente cuando esa anticipación se ve corroborada en el fluir mismo de cualquier existencia. Estas consideraciones afloran recurrentemente en la obra Ser y tiempo (parágrafos 50, 52, $57,62,64 \ldots$ ) especialmente cuando su autor habla de la estructura del cuidado, con reflexiones como las que siguen:

Solo así podrá aclararse en qué medida es posible en el Dasein mismo, conforme a su estructura de ser, una integridad lograda por medio del estar vuelto hacia el fin. La constitución fundamental del Dasein se hizo visible como cuidado. El significado ontológico de esta expresión fue formulado en la siguiente "definición": anticiparse-a-síestando-ya-en (el mundo) en-medio del ente que comparece (dentro del mundo). Quedan así expresados los caracteres fundamentales del ser del Dasein: en el anticiparse-a-sí, la existencia; en el estar-yaen..., la facticidad; en el estar en medio de..., la caída ${ }^{61}$.

Este texto expresa de una manera significativa los asertos fundamentales de la primera filosofía de Heidegger y conecta con la problemática que venimos exponiendo. El ser humano tiene que construir su propia existencia, ya que constitutivamente es lo abierto y todavía por realizar. Por este motivo, está llamado a cuidar de su propio existir. De ahí que el cuidado (Sorge) sea el existencial fundamental de la fenomenología que nos ofrece el pensador alemán. Este cuidado supone un ponerse fuera de sí (ex-sistere) anticipando posibilidades, porque el ser humano es proyectivo, un ser de posibilidades. Así pues, la anticipación está inscrita en la propia estructura del Dasein y sería imposible serlo sin dicho carácter anticipatorio. Este existencial, perteneciendo ontológicamente a la estructura del ser-ahí, ni es relativo, ni es prescindible. Otra cosa muy distinta será la concreción óntico-existencial que cada uno otorgue a esta estructura anticipatoria. De este modo, Heidegger escapa a una cierta deriva relativista, a propósito del historicismo de Dilthey, propo-

\footnotetext{
60 Cf. M. Frajó, El sentido de la historia. Introducción al pensamiento de W. Pannenberg (Cristiandad, Madrid 1986) 129-132.

61 M. Heidegger, Ser y Tiempo, $\$ 50$.
} 
niendo una cuestión crucial de toda existencia personal e histórica: el estar vueltos hacia el fin de modo anticipatorio.

Pannenberg se va a preguntar si esto que Heidegger aduce en referencia a la historia individual, podría también aplicarse a la historia univer$\mathrm{sal}^{62}$. Y es aquí donde entronca con su concepto de revelación entendida desde la constitutiva mediación de los hechos históricos. El cristianismo afirma que se da una anticipación, en la inmanencia de la historia, del final definitivo de la misma. En efecto, la revelación entendida como historia significa que Dios se manifiesta a través de sus obras. La obra por antonomasia que Dios ha hecho en la historia es, evidentemente, la resurrección de su $\mathrm{Hijo}^{63}$. O también, la resurrección de Cristo es escatología y, en ella, el futuro cumplido se nos otorga, como anticipo, en el hoy de nuestro tiempo. Así pues, una de las categorías básicas de su propuesta teológica es la categoría de "cumplimiento". En palabras de Pannenberg:

La fe cristiana tiene conocimiento de un acontecimiento de esta índole, por el cual el fin de la historia se torna presente en mitad de esa misma historia. Dicho acontecimiento es la resurrección de Jesús, la anticipación del acontecimiento escatológico en cuya venida confiaban los judíos en este ser humano único en mitad del curso todavía inacabado de la historia. Con todo, es preciso reconocer que solo alguien que confíe en la existencia de un Dios que como creador todopoderoso "da vida a los muertos y llama a la existencia lo que no existe" $(\mathrm{Rm} 4,17)$, puede tener fe en que tal acontecimiento ha tenido realmente lugar en la historia ${ }^{64}$.

De este modo, el cristianismo es capaz de hablar de qué sea la realidad, sobre la base de este acontecimiento anticipatorio de Dios en la historia, la resurrección de su Hijo, que además es el hecho revelatorio por excelencia. Panennberg se preguntará si esto es irracional o mitológico. La respuesta a esta cuestión será negativa. Como hemos expuesto anteriormente, también la razón histórica está permanentemente enunciando significados sobre la base de un adelanto del futuro, que está basado en la fantasía. Por lo tanto, la relación entre la razón y la fe no

62 Cf. M. Fraijó, El sentido de la historia, 164-204.

63 Para esta cuestión, Cf. R. BlÁZQUez, La resurrección en la cristología de W. Pannenberg (Eset, Vitoria 1976) 141-205.

64 W. Pannenberg, Una historia, 353. Cf. también W. Pannenberg, “¿Qué es la verdad?", 74. 
se establece, como se ha creído tradicionalmente, en la distinción entre lo "visible" y lo "invisible". La razón también se sustenta sobre lo invisible porque hace un adelanto fantasioso, y no cumplido, para dotar de significación en el presente a la historia personal y colectiva. Afirma Pannenberg:

No se puede decir que esta razón, al contrario que la fe, tiene que ver solamente con lo visible; tampoco se puede decir de forma ilimitada que la razón, al contrario que la fe y la conciencia, solamente tenga que ver con el dominio. En ambos casos, significaría un reduccionismo de la razón, cuando de otra manera cada pensamiento, cada ocurrencia de la fantasía proviene de aquella totalidad anticipada atemáticamente, a la cual apunta Heidegger cuando dice que las palabras del lenguaje brotan del "sonido del silencio"65.

Estas afirmaciones se pueden corroborar, de un modo manifiesto, atendiendo a una de las derivaciones más significativas de la racionalidad moderna: los grandes movimientos utópicos e ideológicos. Cuando estos distintos movimientos, tanto burgueses como revolucionarios, plantean sus postulados, la cuestión determinante siempre es un adelanto proléptico del final de la historia ${ }^{66}$. La ensoñación de un paraíso intramundano, que posee distintas coloraciones, dependiendo del movimiento ideológico que lo secunde, tiene siempre que ver con dicho adelanto. Por tanto, hay un elemento determinante de la racionalidad moderna que la convierte en racionalidad histórica, es decir, una razón constitutivamente abierta a una anticipación, tremendamente operativa en el plano de la praxis, de aquello que será. Y lo mismo podría decirse de la racionalidad científica: desde una concepción evolutiva del universo, otorga diversas significaciones a la realidad a partir de un adelanto anticipatorio del fin de dicho proceso ${ }^{67}$.

Así pues, la relación entre razón y fe no es una relación entre lo visible y lo invisible, sino que es la relación entre dos invisibles. Por tanto, es necesario un juego de correlación hermenéutica para mostrar quién es capaz de iluminar con mayor plausibilidad el conjunto de lo real. En efecto, ¿dónde podemos encontrar un icono eficaz de ese futuro cum-

\footnotetext{
W. Pannenberg, "Glaube", 250.

Cf. W. Pannenberg, “Tesis”, 125.

67 Cf., para ahondar estas cuestiones, J. Habermas, Pensamiento postmetafísico (Taurus, Madrid 1990) 155-187 y F.J. Hinkelammert, Crítica de la razón utópica (Desclée de Brouwer, Bilbao 2002) 367-390.
} 
plido que nos será otorgado por Dios? En la resurrección de Cristo. En este acontecimiento vemos la humanidad nueva, un anticipo de aquello a lo que todos estamos llamados a ser. También podemos contemplar las llagas que han sido superadas por el evento del amor resucitado de Dios Padre con respecto a su Hijo crucificado. En el evento de Cristo resucitado somos capaces de percibir que el ser humano no está destinado a la muerte, sino a la vida. Además, este evento escatológico pone de manifiesto la vocación universalista del cristianismo y la necesidad, a juicio de Pannenberg, de que la historia no sea un descompuesto de instantes, sino el sucederse solidario del tiempo conducido hasta una meta. En definitiva, si la realidad está de cara al futuro, lo cual manifiesta la ontología propia de nuestro autor, y la resurrección de Jesús es una anticipación de ese futuro definitivo, podemos extraer los contenidos inherentes al acontecimiento de la pascua para explicitar la visión cristiana del mundo en diálogo con otras posibles cosmovisiones ${ }^{68}$.

No obstante, permanece una neta diferenciación entre la razón y la $\mathrm{fe}^{69}$. Mientras la primera está focalizada básicamente hacia el presente, aunque sea sobre dicho presupuesto absoluto no expresado, que a veces incluso puede llegar a olvidar, la segunda vive esencialmente desde la orientación hacia ese futuro escatológico. De ahí que Pannenberg afirme que ambas no solo no se hallan enfrentadas, sino que la fe puede ayudar a la razón a hacerse clara a sí misma. La fe ofrece, como servicio a la razón, el recuerdo permanente de aquel futuro no expresado y que, sin embargo, le es constitutivo.

\section{Conclusión}

La teología tiene que partir siempre de dos presupuestos ineludibles: la escucha de la revelación de Dios en Cristo, como presupuesto determinante de su quehacer, y la escucha del tiempo y de los otros, como presupuesto condicionante de la reflexión creyente. Ahora bien, aquella tarea que se inscribe dentro de la libertad propia del teólogo, en la ejercitación de su oficio, es la búsqueda, con la creatividad subsiguiente, de un principio formal-fundamental que sea capaz de anudar esos dos

\footnotetext{
68 Cf. W. Pannenberg, Fundamentos, 82-92. Para esta cuestión, Cf. también R. BLÁzQUEZ, La resurrección, 207-449.

69 Cf. W. Pannenberg, "Glaube", 250s.
} 
presupuestos en una síntesis nueva y lograda, volviendo a poner en acto la dimensión de credibilidad del propio cristianismo ${ }^{70}$.

Cuando hablamos del principio formal-fundamental, no nos referimos a unos determinados contenidos esenciales que se ponen en juego, sino a la manera en la que esos contenidos podrían ser asumidos como significativos por un interlocutor contemporáneo. Es así como reivindicamos la naturaleza profundamente histórica de la labor teológica. Esta apelación al principio formal-fundamental de una determinada propuesta teológica es la que también explica que no se deba hablar de teología perenne, ya que toda teología está marcada con las heridas del tiempo en el que le ha tocado peregrinar y, por ende, dicha teología pasará cuando los problemas se tornen nuevos y distintos ${ }^{71}$.

El primer Barth, objeto aquí de nuestra atención, encuentra en un "principio de carácter dialéctico" el aspecto formal que da unidad y coherencia a toda su propuesta teológica. Es esta diferencia dialéctica la que ha encontrado en la Palabra de Dios, yendo más allá de una lectura literal de los textos, pero dejándose inspirar por el objeto puro de la fe. La escucha de su tiempo histórico le lleva a la convicción de que es intolerable la supresión de la infinita diferencia que separa el cielo de la tierra. Así pues, decir al Dios de Jesucristo consistirá, a su juicio, en denunciar cualquier sistema que tienda a la confusión de lo divino con lo humano, en una suerte de pretensiosa reconciliación. No es extraño, pues, que sus referentes filosóficos partan de la lectura de Kierkegaard, conocido por su honesta discrepancia con Hegel y su apelación, en un tiempo profundamente ideológico, a la infinita dignidad de lo singular. Este principio dialéctico impregna el conjunto de su obra y determina la manera concreta en la que el teólogo afronta todos y cada uno de los elementos definitorios del cristianismo.

Pannenberg, que algunos catalogan como el más católico de los protestantes, aporta un "principio formal de carácter anticipatorio" para articular su propuesta teológica. Por una parte, reconoce en la mutación histórica de la razón, la declinación más significativa que se ha producido en la modernidad. Al mismo tiempo, entiende que la manifestación

70 S. BÉJAR, "La libertad del teólogo en su oficio", en C. Alonso Bedate (ed.), La libertad: ilusiones y limites (Universidad Pontificia Comillas, Madrid 2009) 61-74.

71 Cf. B. DE Solages, "Pour l'honneur de la Théologie", Bulletin de littérature ecclésiastique 48 (1947) 65-84. 
de Dios al ser humano siempre se ha realizado, no de un modo directo, sino en la mediación de sus gestas históricas. De esta manera, Pannenberg intuye que razón y fe no son cantidades heterogéneas, ya que ambas comparten una constitutiva apertura al futuro. Así, y desde esta caracterización anticipatoria de la razón histórica, la teología consistirá en una tarea propiamente hermenéutica, donde se intenta poner al descubierto los presupuestos, no siempre suficientemente reconocidos, de la racionalidad moderna. En efecto, el cristianismo tiene en la resurrección de Cristo un adelanto proléptico del final de la historia, al igual que la razón otorga significados al conjunto de lo real sobre la base de ciertas prolepsis fundadas en la fantasía. Podemos reconocer aquí un eco del tránsito desde Hegel hasta Dilthey y la necesidad de mostrar, frente a todo intento de historicismo relativista, la posibilidad de una mediación del Absoluto en la historia. 